\title{
An investigation on the characterization of activated carbon from areca leaves and their adsorption nature towards different dyes
}

\author{
Basrur D. and Ishwara Bhat J.* \\ Department of Chemistry, Mangalore University, Mangalagangothri - 574199, Karnataka, India \\ Received: 29/08/2018, Accepted: 02/12/2018, Available online: 07/01/2019 \\ *to whom all correspondence should be addressed: e-mail: bhatij08@gmail.com \\ https://doi.org/10.30955/gnj.002877
}

\begin{abstract}
In this study activated carbon is produced from areca plant leaves, an agricultural waste material. The physical and chemical structural characterisation of the prepared carbon was carried out by FTIR, TGA and XRD analysis. FTIR study showed the presence of several functional groups, such as $\mathrm{C}=\mathrm{O}, \mathrm{C}=\mathrm{C}, \mathrm{OH}, \mathrm{NH}$ on the surface of the activated carbon. To determine the adsorption efficiency, studies were carried out using cationic and anionic dyes and it was found to be dependent on contact time, temperature and concentration of the solution. The experimental data obtained were correlated with the Langmuir, Freundlich isotherm model. Kinetic data were obtained using second order rate equation. Probable mechanism of adsorption process with the dyes was analysed. As the prepared carbon is cost efficient, abundant and has high uptake capacity, it can be used as an adsorbent for fresh water or waste water treatment. It could be considered as promising material for the removal of dyes.
\end{abstract}

Keywords: Areca leaf, crystalline index, Congo red, pyrolysis, cellulose, adsorption, isotherm, Freundlich, Langmuir, kinetics.

\section{Introduction}

Among the options available for the treatment of waste water such as filtration, biological methods, adsorption, electrolysis and activated sludge, the adsorption can be considered as the most effective method because of its simple design and manageable operation technique (Iqbal and Ashiq, 2006). Generally activated carbon (AC) is used as an adsorbent for removal of hazardous materials mainly from the aqueous phase. Application of activated carbon from biodegradable product is turned out to be benefit over the commercial carbon and this has encouraged the researchers in the use of different agricultural waste. Rice husk (Mohanty et al., 2006), date stone (Bouchelta et al., 2008), olive stones (El-Sheikh et al., 2004), apricot core, grape stalk (Martinez et al., 2009), maize cob (Ketcha et al., 2012), coconut shell (Yang et al., 2010), Zapota seed ( Nath et al., 2008), aloevera green (Omidi et al., 2015) etc. have been studied as raw materials and found to be preferable raw materials for the preparation of activated carbon. Researchers have also studied the preparation of activated carbon from different types of leaves and analyzed the adsorption capacity for the removal of dyes and heavy metal ions from aqueous phase (Shidvash et al., 2014; Elhussien et al., 2017).

Areca (Latin name: Areca catechu) is the main commercial crop grown in India, mainly in some parts of Karnataka. Beside the areca nut, areca plant leaves are also gaining the commercial importance as its sheaths are used for making cups, plates and hats. This study is an attempt to utilize the activated carbon obtained from unused areca plant leaves for adsorption applications. Up to the present only few adsorption studies have been carried out by making use of areca components. Activated carbon from areca nut, areca husk, areca coir and heart wood have been exclusively studied as adsorbent for the removal of dyes, acid and heavy metal ions (Joshi and adhikari, 2016; Muslim et al., 2017; Hemashree et al., 2016; Haloi et al., 2011; Chakrabarty et al., 2011). Congo red (CR) is a benzidine bisazo-dye which has variety of applications such as textile dying, indicator, biological stain etc. It is mainly found in textile, paper, printing and leather industrial effluents. Congo red is metabolized to benzidine, a carcinogen and exposure to this can lead to allergic responses. Also it is very difficult to remove owing to its complex aromatic structure which provides physico-chemical and thermal stability (Chatwal, 2004; Rauf et al., 2015). Crystal violet (CV) is one of the aminotriphenyl methane dyes, which is used as textile dye, in making indelible ink, stamping pad etc. As crystal violet is mutagen and mitotic poison, the industrial effluents which contain crystal violet must be treated to reduce its influence on water pollution (Doke et al., 2016). Literature indicates that so far no work has been reported on the use of areca plant leaves for the preparation of activated carbon. The current study focuses on converting areca leaves, low cost agricultural raw materials, to activated carbon and evaluation of its dye adsorption capacity. 


\section{Materials and methods}

\subsection{Preparation of activated carbon}

Areca leaves were used as the raw material for the preparation of activated carbon. The collected leaves were cleaned, washed and later dried in hot air oven at $110^{\circ} \mathrm{C}$ for an hour. Three different methods were adopted for the preparation of activated carbon. For the physical activated carbon, finely powdered leaf sample was carbonized at $300^{\circ} \mathrm{C}$ for an hour in a muffle furnace and labelled as PALC. For chemical activation, leaves were soaked in $10 \% \mathrm{ZnCl}_{2}$ solution for 24 hours. The sample was taken out, dried and carbonised at $300^{\circ} \mathrm{C}$ in muffle furnace. The obtained activated carbon was washed with hot water then with distilled water and later dried and labelled as ZALC. For microwave treatment, the powdered precursor was irradiated for 60 minutes (Microwave power $90 \mathrm{~W}$, Energy $\approx 270$ Joules/Sec) and the carbon obtained was labelled as MALC.

\subsection{Characterization of the activated carbon}

Fourier Transform Infrared Spectrometer (Nicolet, Impact - 410, USA) was used to identify the functional groups present in areca leaf and prepared activated carbon. Crystal structure of the activated carbon was analysed by X-ray diffraction method Rigaku Minifles 600 Japan). Sigma Series Field Emission Scanning Electron Microscope (Ziess) was made use to characterize the surface structure of the activated carbon. Thermal stability of the raw areca leaf and activated carbon were studied by a thermogravimetric analyzer SDT Q600 V20.9 (Japan) which measures weight loss of the samples in relation to the temperature.

\subsection{Adsorption studies}

Adsorption study was carried out by adding up a fixed amount of activated carbon to $50 \mathrm{ml}$ of the dye solution in a Erlenmeyer flask and stirred up for a definite interval of time. Dye solution was filtered and the concentration of filtered solution was determined by using UV-Visible spectrophotometer. The amount of dye adsorbed, $q_{e}(\mathrm{mg} / \mathrm{g})$, by adsorbent at time $t$, was calculated by the eqn:

$q_{e}=\frac{\left(C_{o}-C_{e}\right) V}{W}$

where $C_{o}$ and $C_{e}$ are initial and equilibrium concentration $(\mathrm{mg} / \mathrm{L}), \mathrm{V}$ is volume of solution $(\mathrm{L})$ and $\mathrm{W}$ is the mass of the adsorbate (g)

\section{Results and discussion}

\subsection{Characterization of activated carbon}

\subsubsection{FTIR analysis}

Adsorption properties of activated carbon are greatly influenced by the presence of functional groups with hetero atoms or $\pi$-electron on their surface. FTIR technique was adopted for the determination of the functional groups present on the surface of activated carbon. Figure 1 demonstrates the FTIR spectrum of areca leaf and activated carbon (PALC, ZALC and MALC).
The broad absorption band formed at $3303 \mathrm{~cm}^{-1}$ (Figure 1a) may be due to the intermingling of $\mathrm{OH}$ and $\mathrm{NH}$ peaks. The peaks at $2920 \mathrm{~cm}^{-1}$ and $2852 \mathrm{~cm}^{-1}$ suggested the existence of some aliphatic groups on the carbon. The peak formed at $1733 \mathrm{~cm}^{-1}$ is due to stretching of $\mathrm{C}=\mathrm{O}$ bond for esters groups of hemicelluloses or the ester linkages of carboxylic group of lignin or hemicelluloses (Nabili et al., 2016). The bands at $1657 \mathrm{~cm}^{-1}$ and $1517 \mathrm{~cm}^{-1}$ are due to bending of primary and secondary amine group respectively and the peak at $1238 \mathrm{~cm}^{-1}$ may be due to $\mathrm{C}-\mathrm{N}$ stretching. The peaks formed at $1606 \mathrm{~cm}^{-1}$ and $1450 \mathrm{~cm}^{-1}$ may be due to stretching of $\mathrm{C}=\mathrm{C}$ bonds and peak visible at $1157 \mathrm{~cm}^{-1}$ may be due to C-O stretching (Lampman et al., 2013). The peaks in the range $1000-500 \mathrm{~cm}^{-1}$ are due to out-of-plane bending of olefinic $\mathrm{C}-\mathrm{H}$ groups and also due to the substituted aromatic rings (Lampman et al., 2013; Kemp, 1991). Small variation in the intensities of spectra of different carbon may be due to the adaption of different methods for the carbon preparation.
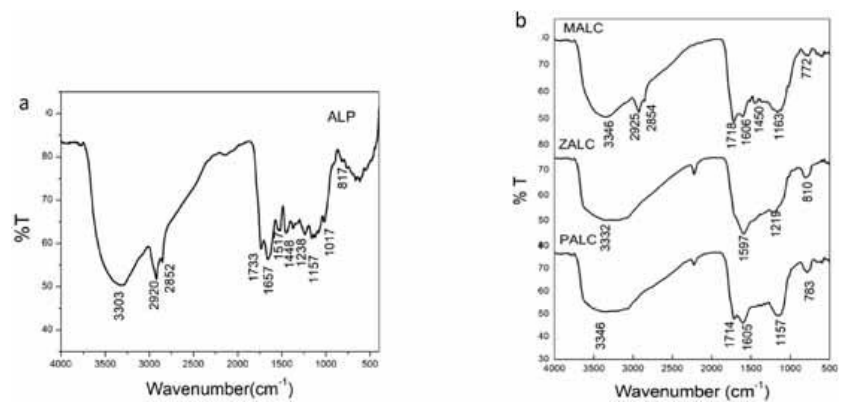

Figure 1. (a) FTIR spectra for areca leaf (b) FTIR spectra for activated carbon

It is apparent from the Figure 1(b) that spectrum obtained for the activated carbon is not the same as that of areca leaf. Various peaks which are liable for $\mathrm{NH}, \mathrm{OH}, \mathrm{C}=\mathrm{O}, \mathrm{C}-\mathrm{O}$ bonds are continued to be present in the spectra of activated carbon. Disappearance of a few peaks in the spectra of activated carbon could be to due to decomposition of some of the functional groups or dissipation of some of the volatile components at higher temperature $\left(>300^{\circ} \mathrm{C}\right)$ in the course of the preparation of activated carbon. IR results confirmed the presence of functional groups such as $-\mathrm{OH},-\mathrm{NH}, \mathrm{C}=\mathrm{O}, \mathrm{C}=\mathrm{C}, \mathrm{CO}$ and $\mathrm{CH}$ on the surface of prepared activated carbon and these functional groups are expected to act as active sites for the adsorption of the dye molecules. Hence the prepared carbon can be considered as a potential adsorbent.

\subsubsection{Thermal analysis}

Figure 2 shows the obtained thermogravimetric curves for areca leaf powder (ALP) and the prepared activated carbon. TGA curve of ALP showed that the decomposition of leaf occurred in three phases and this decomposition phases are due to degradation of cellulose, hemicelluloses and lignin present in the leaf. The mass loss in the first stage is due to evaporation of moisture contents present in the leaf. Weight loss in the second phase is the result of the thermal decomposition of the cellulose and hemicellulose $\left(200-400^{\circ} \mathrm{C}\right)$ and weight loss in the last 
phase $\left(400-600^{\circ} \mathrm{C}\right)$ may be due to degradation of cellulose and lignin (Muller-Hagedorn et al., 2003). Unchanged weight loss above $600^{\circ} \mathrm{C}$ indicated complete degradation or the stability of the left over areca leaf.

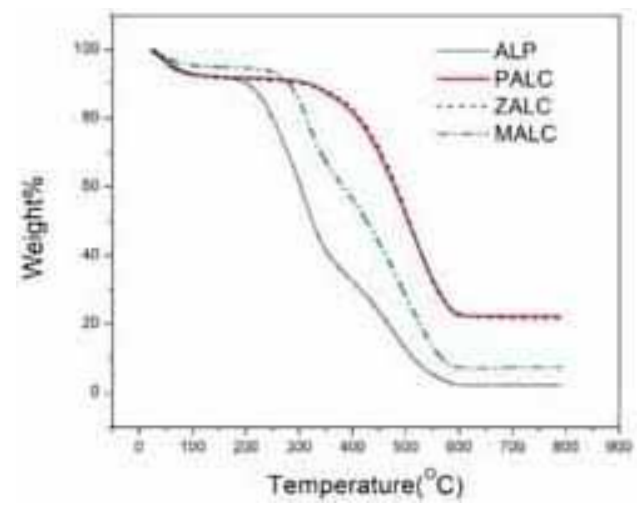

Figure 2. Thermo gravimetric curve of ALP and activated carbon

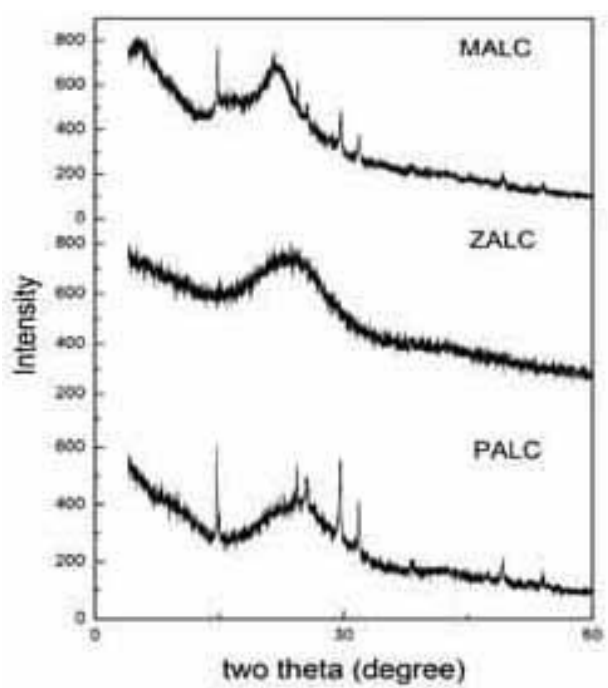

Figure 3. XRD pattern for activated carbon

Slight variation was observed at initial decomposition temperature of thermal treated carbon and microwave treated carbon which could be due to the degradation of chemical constituent present in the different carbon. Here, weight loss in the first phase is due to the vaporization of moisture retained in the carbon, where as the rapid and major weight loss may be due to pyrolysis of hemicellulose and cellulose.

\subsection{3. $X$ ray diffraction analysis}

Crystallographic characters of the activated carbon were determined by $\mathrm{X}$ ray diffraction with $\mathrm{Cu}-\mathrm{K} \alpha$ radiation $(\lambda=1.5418$ A $)$. Obtained XRD pattern of the activated carbon is shown in Figure 3. Presence of some sharp peaks indicated that both PALC and MALC are the mixture of amorphous and microcrystalline species (Radovic et al., 2001). Inter planar distance $d$, hkl values and cell volume, $a^{3}$ were determined using obtained peak values and the calculated data are shown in Table 1 . The inter layer spacing $d$ is determined by Bragg's equation: $d=\frac{\lambda}{2 \sin \theta}$

where $\lambda=1.5418 \AA$ and $\theta$ is the scattering angle. Crystallinty index (Crl) is a quantitative indicator of crystallinity which has been used to depict the relative amount of crystalline material in a given substance [Sa et al., 2017; Park et al., 2010). The crystalline index of the carbon was determined using the method proposed by Segal et al. (Lin et al., 2013) and the equation is given as:

$\mathrm{Crl}=\left(\frac{\mathrm{I}_{002}-\mathrm{I}_{\mathrm{am}}}{\mathrm{I}_{002}}\right)$

where $l_{002}$ is the overall intensity of the peak at $2 \theta$ about $22^{\circ}$ and lam is the intensity of the baseline at about $18^{\circ}$.

Low values of $\mathrm{Crl}$ suggest that the amorphous form of carbon is in a greater extent in activated carbon (Park et al., 2010). Also small values of crystallite size indicate the higher adsorption capacity of activated carbon.

\subsection{Adsorption studies}

\subsubsection{Effect of contact time}

The after-effect of contact time on uptake of dye was studied in the range of 15-120 minutes to find out the equilibrium time for the adsorption. Result indicated that initially rate of removal of dye from aqueous solution increased rapidly and reached maximum at 60 minutes with a later decrease in adsorption. It can be said that further continuing in time has no effect on the adsorption rate, and instead found is decrease in adsorption rate. This says that after reaching a maximum value no more adsorption has taken place or bond has formed between the adsorbate and adsorbent. In the beginning, sharp increase in the rate of adsorption is due to larger surface area and availability of vacant sites on the adsorbent. After reaching equilibrium time, repulsive force between the adsorbate and the adsorbent lead to the decrement of adsorption capacity. Hence further increase in contact time did not show any appreciable variation in adsorption behaviour.

\subsubsection{Adsorption kinetics}

Kinetic study of adsorption process provides information on the reaction rate and also on the dependence of adsorption rates on various factors (Dotto et al., 2011). The obtained data were analysed using first order model. First order kinetic model is expressed as (Dehghani et al., 2016):

$\log \left(q_{e}-q_{t}\right)=\log q_{e}-\frac{k_{1}}{2.303} t$

where $k_{1}\left(\mathrm{~min}^{-1}\right)$ is the rate constant of the first order adsorption and $q_{t}$ is the adsorption capacity at time $(\mathrm{mg} / \mathrm{g})$. As the expected linearity for the plot of $\log \left(q_{e}-q_{t}\right)$ vs. time, $t$ was not observed, second order kinetic model was used to fit the obtained data. The second-order kinetic model is given as (Boussahel et al., 2009): 


$$
\frac{t}{q_{t}}=\frac{1}{k_{2} q_{e}^{2}}+\frac{1}{q_{e}} t
$$

where $q_{e}$ and $q_{t}$ are the adsorption capacities at equilibrium and at given time, $t$ respectively and $k_{2}$ is the equilibrium rate constant of second order adsorption. $k_{2}$ was determined from the slope and intercept from the $t / q_{t}$ vs. $t$ plot (Figure $4(a)$ and $\left.4(b)\right)$. Adsorption data were well described by second order kinetics. The rate constant, $k_{2}$ found to be very high for crystal violet compared to congo red and this can be attributed to the higher electrostatic interaction of activated carbon towards cationic dye compared to anionic dye. Study also showed that MALC exhibited higher rate constant and this could be due to larger basic nature of MALC compared to PALC and ZALC. The decrease in the capacity of congo red adsorption on to MALC is due to the electrostatic repulsion between the basic surface group and the deprotonated congo red molecule. This is in conformity with the results obtained under FTIR study.

Table 1. XRD data for Activated carbon

\begin{tabular}{|c|c|c|c|c|c|c|c|}
\hline Sample & $\begin{array}{c}2 \theta \\
\text { (degree) } \\
\end{array}$ & $d(\AA ̊)$ & $\mathbf{N}$ & hkl & a (Å) & Cell volume $(a)^{3}$ & Crystalline Index (Crl) \\
\hline \multirow{5}{*}{ PALC } & 24.40 & 3.65 & 1 & 100 & 3.65 & \multirow{5}{*}{31.86} & \multirow{5}{*}{22.43} \\
\hline & 25.46 & 3.49 & 1 & 100 & 3.49 & & \\
\hline & 29.61 & 3.01 & 1 & 100 & 3.01 & & \\
\hline & 31.82 & 2.81 & 1 & 100 & 2.81 & & \\
\hline & 49.16 & 1.85 & 2 & 110 & 1.85 & & \\
\hline \multirow{4}{*}{ MALC } & 21.70 & 4.09 & 1 & 100 & 4.09 & \multirow{4}{*}{41.53} & \multirow{4}{*}{26.79} \\
\hline & 24.49 & 3.63 & 1 & 100 & 3.63 & & \\
\hline & 29.69 & 3.00 & 1 & 100 & 3.00 & & \\
\hline & 31.88 & 2.80 & 1 & 100 & 2.80 & & \\
\hline \multirow{4}{*}{ ZALC } & 22.55 & 3.94 & 1 & 100 & 3.94 & \multirow{4}{*}{50.69} & \multirow{4}{*}{24.43} \\
\hline & 23.62 & 3.76 & 1 & 100 & 3.76 & & \\
\hline & 24.73 & 3.60 & 1 & 100 & 3.60 & & \\
\hline & 25.78 & 3.45 & 1 & 100 & 3.45 & & \\
\hline
\end{tabular}

Table 2. Second order kinetic parameters for the adsorption of CV and CR

\begin{tabular}{ccccccc}
\hline \multirow{2}{*}{ Sample } & \multicolumn{3}{c}{ Crystal Violet } & \multicolumn{3}{c}{ Congo red } \\
\cline { 2 - 7 } & $\begin{array}{c}\mathbf{k}_{\mathbf{2}} \times \mathbf{1 0}^{-\mathbf{2}} \\
(\mathbf{g} / \mathbf{m g} / \mathbf{m i n})\end{array}$ & $\mathbf{q}_{\mathbf{e}}(\mathbf{m g} / \mathbf{g})$ & $\mathbf{R}^{\mathbf{2}}$ & $\begin{array}{c}\mathbf{k}_{2} \times 10^{-3} \\
(\mathbf{g} / \mathbf{m g} / \mathbf{m i n})\end{array}$ & $\mathbf{q}_{\mathbf{e}}(\mathbf{m g} / \mathbf{g})$ & $\mathbf{R}^{\mathbf{2}}$ \\
\hline PALC & 10.78 & 27.80 & 0.99 & 5.82 & 26.24 & 0.99 \\
\hline MALC & 14.13 & 28.04 & 0.99 & 5.40 & 23.47 & 0.99 \\
\hline ZALC & 7.88 & 27.32 & 0.99 & 4.99 & 20.47 & 0.99 \\
\hline
\end{tabular}

Table 3. Isotherm parameters for the adsorption of CV and CR on to activated carbon

\begin{tabular}{|c|c|c|c|c|c|c|c|}
\hline \multirow{2}{*}{ Sample } & \multirow{2}{*}{ Dye } & \multicolumn{3}{|c|}{ Langmuir Constant } & \multicolumn{3}{|c|}{ Freundlich Constant } \\
\hline & & $\mathbf{Q}^{\circ}$ & $\mathrm{K}_{\mathrm{L}}$ & $\mathbf{R}^{2}$ & $K_{f}$ & $\mathrm{n}$ & $\mathbf{R}^{2}$ \\
\hline PALC & \multirow{3}{*}{$\mathrm{CV}$} & 59.52 & 0.26 & 0.97 & 12.82 & 1.81 & 0.98 \\
\hline MALC & & 58.82 & 0.34 & 0.96 & 14.96 & 1.89 & 0.99 \\
\hline ZALC & & 78.74 & 0.11 & 0.97 & 8.73 & 1.45 & 0.98 \\
\hline PALC & \multirow{3}{*}{ CR } & 44.44 & 0.12 & 0.99 & 6.83 & 1.97 & 0.96 \\
\hline MALC & & 34.01 & 0.05 & 0.99 & 3.41 & 1.90 & 0.96 \\
\hline ZALC & & 32.25 & 0.04 & 0.99 & 2.54 & 1.76 & 0.96 \\
\hline
\end{tabular}

Table 4. Results thermodynamic parameters for the adsorption for $\mathrm{CV}$ and $\mathrm{CR}$ on $\mathrm{AC}$

\begin{tabular}{ccccccccc}
\hline Sample & $\begin{array}{c}\Delta \mathbf{H}^{\circ} \\
(\mathbf{k J} / \mathbf{m o l})\end{array}$ & $\begin{array}{c}\Delta \mathbf{S}^{\circ} \\
(\mathbf{k J} / \mathbf{m o l} / \mathbf{K})\end{array}$ & $\begin{array}{c}\Delta \mathbf{G}^{\circ} \\
(\mathbf{k J} / \mathbf{m o l})\end{array}$ & $\mathbf{E}_{\mathbf{a}}(\mathbf{k J} / \mathbf{m o l})$ & $\begin{array}{c}\Delta \mathbf{H}^{\circ} \\
(\mathbf{k J} / \mathbf{m o l})\end{array}$ & $\begin{array}{c}\Delta \mathbf{S}^{\circ} \\
(\mathbf{k J} / \mathbf{m o l} / \mathbf{K})\end{array}$ & $\begin{array}{c}\Delta \mathbf{G}^{\circ} \\
(\mathbf{k J} / \mathbf{m o l})\end{array}$ & $\mathbf{E}_{\mathbf{a}}(\mathbf{k J} / \mathbf{m o l})$ \\
\hline PALC & 23.81 & 0.100 & -6.48 & 26.30 & 23.28 & 0.096 & -5.62 & 25.78 \\
\hline MALC & 21.82 & 0.095 & -6.88 & 24.31 & 25.67 & 0.102 & -5.06 & 28.16 \\
\hline ZALC & 25.03 & 0.103 & -5.99 & 27.52 & 26.47 & 0.100 & -3.55 & 28.96 \\
\hline
\end{tabular}

\subsubsection{Adsorption isotherms}

Adsorption isotherm was studied by Langmuir and Freundlich isotherm models. The Langmuir equation is used to explain single layer and uniform adsorption (Belhachemi and Addoun, 2011). The linear form of Langmuir equation is represented as (Amri et al., 2009):

$\frac{\mathrm{C}_{e}}{\mathrm{q}_{\mathrm{e}}}=\frac{1}{\mathrm{~K}_{\mathrm{L}} \mathrm{Q}^{\circ}}+\frac{\mathrm{C}_{\mathrm{e}}}{\mathrm{Q}^{\circ}}$ where $C_{e}$ is the equilibrium liquid phase concentration $(\mathrm{mg} / \mathrm{L}), \mathrm{q}_{\mathrm{e}}$ is the amount of adsorbate adsorbed $(\mathrm{mg} / \mathrm{g}), \mathrm{Q}^{\circ}$ is the maximum adsorption capacity $(\mathrm{mg} / \mathrm{g})$ and $\mathrm{K}_{\mathrm{L}}$ is the Langmuir constant $(\mathrm{L} / \mathrm{mg})$. The values of $\mathrm{Q}^{\circ}$ and $\mathrm{K} L$ were calculated by the slope and intercept obtained from the plot of $C_{e} / q_{e}$ vs. $C_{e}$ (Figure 5(a) and 5(b)).

The Freundlich model is based on the distribution of solute between the solid at equilibrium ( $\mathrm{Na}$ et al., 2002). 
Logarithmic form of the Freundlich Isotherm is represented as: (Sawyer et al., 1994)

$\log q_{e}=\log K_{f}+\frac{1}{n} \log C_{e}$

where $n$ is the adsorption intensity and $K_{f}$ is the Freundlich adsorption capacity $\left[(\mathrm{mol} / \mathrm{g})(\mathrm{L} / \mathrm{g})^{1 / n}\right]$. The values of $n$ and $K_{f}$ were calculated from the slope and intercept of the plot of $\log q_{e}$ vs. $\log C_{e}$ (Figure 6(a) and 6(b)). From the result it is found that Freundlich isotherm fits better to the data obtained for crystal violet, whereas Langmuir isotherm holds well for the adsorption of congo red. The value of $n$ in the range 1-2 represents agreeable adsorption characteristics (Elhussien et al., 2017). $K$ represents the affinity of the solute with the adsorbent and the higher $K$ value suggested that the prepared carbon has the highest affinity towards crystal violet compared to congo red (Brito et al., 2012).
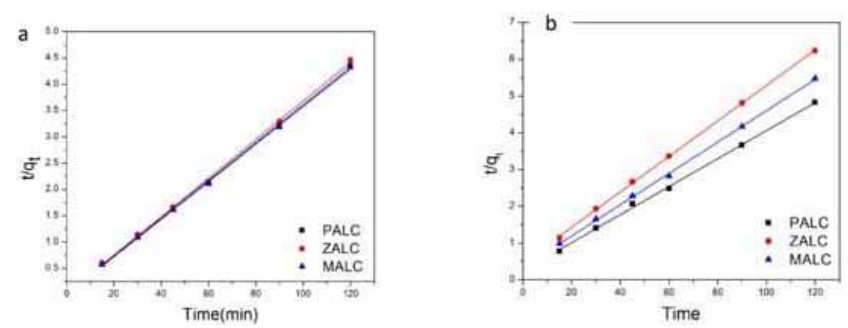

Figure 4. (a) Plot of Second-order kinetic modelling for the CV and (b) CR adsorption
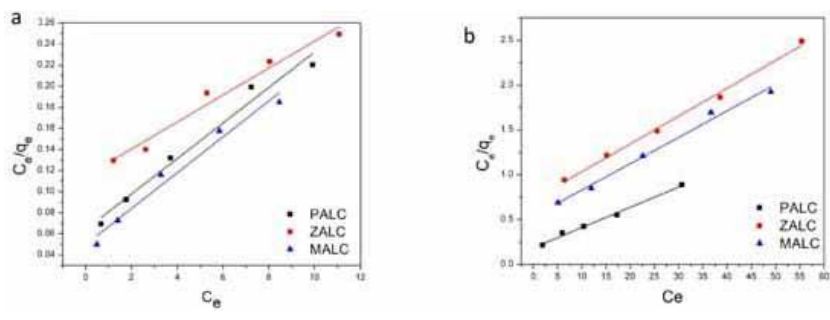

Figure 5. (a) Langmuir Isotherm for CV adsorption and (b) for CR adsorption
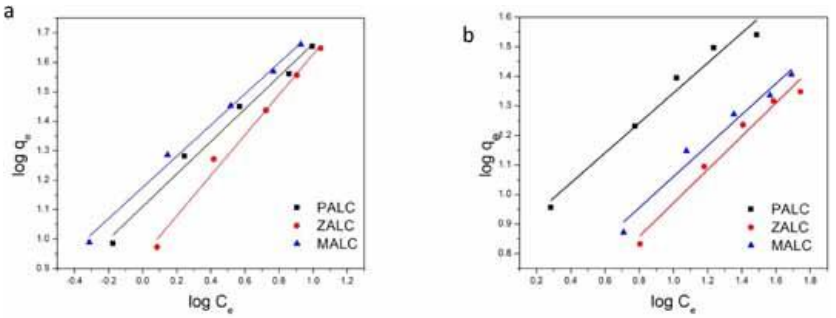

Figure 6. (a) Freundlich Isotherm for CV adsorption (b) for CR adsorption

\subsubsection{Effect of temperature}

The impact of temperature on adsorption of crystal violet and congo red on activated carbon was investigated by carrying out the experiment in the temperature range 10$60^{\circ} \mathrm{C}$ (Figure (7a) and (7b)). Adsorption capacity of prepared carbon increased with rise in temperature from $10-40^{\circ} \mathrm{C}$ and later decreased with further increase in temperature. Maximum adsorption was observed at $40^{\circ} \mathrm{C}$. Increased temperature speeds up the rate of motivity of the solute particles through the liquid to the adsorption sites and the adsorption continues to increase (Cecen and Aktas, 2009). Due to this the surface gets covered faster and probably desorption start after this temperature or even the decomposition of the species of dyes might have taken place. As the molecules move away from each other, interaction between the adsorbate molecules rapidly decreases resulting desorption from surface phase to aqueous phase.
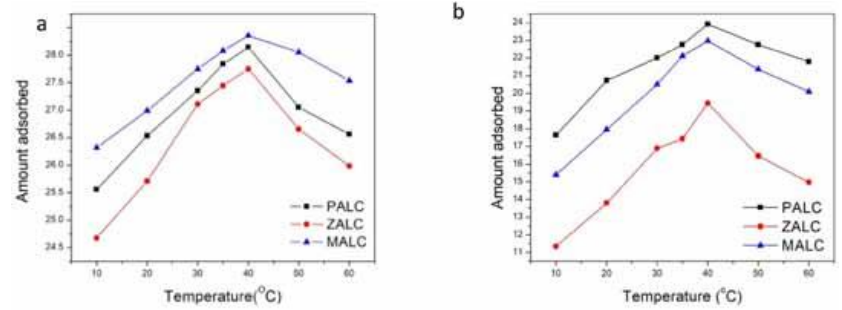

Figure 7. (a) Effect of temperature for CV and (b) CR adsorption

\subsubsection{Adsorption thermodynamic}

The standard free energy, enthalpy and entropy of the adsorption process can be evaluated from the following equations:

$\Delta \mathrm{G}^{\circ}=\mathrm{RT} \ln \mathrm{K}$

$\ln \mathrm{K}=-\frac{\Delta \mathrm{H}^{\circ}}{\mathrm{RT}}+\frac{\Delta \mathrm{S}^{\circ}}{\mathrm{R}}$

where $T$ is the absolute temperature, $R$ is the gas constant and $K_{c}$ is the equilibrium constant, obtained from the following equation:

$K=\frac{q_{e}}{C_{e}}$

where $\mathrm{q}_{\mathrm{e}}$ is the amount of dye adsorbed on activated carbon at equilibrium and $\mathrm{C}_{e}$ is the equilibrium concentration of dye in the solution. The values of $\Delta \mathrm{H}^{\circ}$ and $\Delta \mathrm{S}^{\circ}$ were calculated from the InK vs. $1 / T$ plot (Figure $8(\mathrm{a})$ and $8(\mathrm{~b}))$ and the results obtained are given in Table 4.
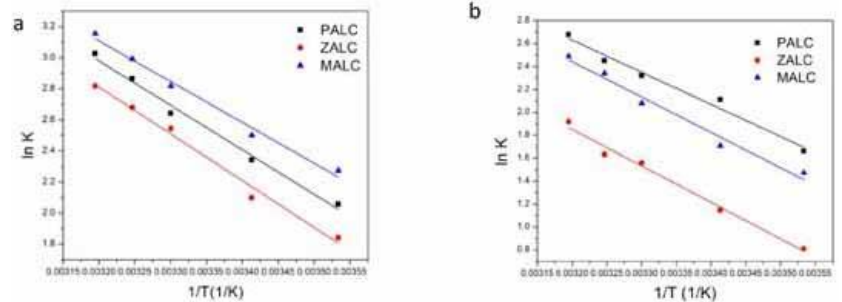

Figure 8. (a) van't Hoff equation for CV and (b) CR adsorption

Decreased values of change in free energy with increasing temperature indicated that greater adsorption occurred at $40^{\circ} \mathrm{C}$ and the process is spontaneous. Positive values of $\Delta H^{\circ}$ reflected the endothermic feature of the adsorption process. Low positive values of $\Delta S^{\circ}$ may be due to swelling 
or dissociative adsorption (Pahari, 2011). Values of activation energy, $24.31 \mathrm{~kJ} / \mathrm{mole}$ and negative values of $\Delta G^{\circ}$ of $\mathrm{CV}$ adsorption on MALC indicated the strong interaction of the MALC towards CV. This is also confirmed by kinetic studies where MALC exhibited maximum rate constant for $\mathrm{CV}$ adsorption.

\subsubsection{Adsorption mechanism}

It is well known fact that adsorption mechanism mainly depends on the factors like pore structure, surface chemistry and polarity of solvents (Goto et al., 2015). Result showed that the behaviour of PALC found to be different than that of MALC towards dye adsorption. Experimental result indicated that MALC found to be effective adsorbent for the uptake of crystal violet and PALC towards congo red. Even though IR results confirmed that there is no much variation in functional group in PALC and MALC, adsorption capacity found to be different for both cationic and anionic dye. May be the basic surface group present on MALC exerts greater affinity towards cationic dye molecules which in turn increases the interaction between dye molecules and adsorbent eventually enhancing rate of adsorption. Presence of $\mathrm{C}=\mathrm{C}$ bonds in MALC which is supported by FTIR analysis may also intensify the electrostatic interaction in adsorption process. The study showed that affinity of MALC towards CV is also governed by hydrogen bonding and $\pi-\pi$ interaction between the aromatic ring of the adsorbate and the graphene layers of the activated carbon ( Bansal and Goyal, 2005; Derylo-Marczewsk et al., 2008). The lower affinity of MALC towards CR may be due the repulsive force between the adsorbent and the anionic dye. It was further observed that ZALC showed least affinity towards cationic dye which is contradictory to the predicted result. Thus, the study demonstrated that adsorption of dye molecules on carbon material not only depends on the functional group but also on specific interactions of dye molecules with active site on carbon surface. It can also be said that porosity also plays major role in the adsorption mechanism of the dyes.

\section{Conclusion}

Activated carbon was produced from areca leaves and characterized and adsorption capacity of the carbon was analyzed by carrying out adsorption study. Langmuir and Freundlich model are conformed for congo red and crystal violet respectively. The process followed second order rate. Result showed that adsorption capacity depend on the functional group as well as porosity of the carbon. Experimental results also showed that the prepared activated carbon can be used as an effective adsorbent which contributes satisfactory elimination of both the cationic and anionic dyes from aqueous phase. Easy availability and more low-cost are the two major advantages of areca leaves for using it as an adsorbent.

\section{References}

Amri N., Zakaria R. and Abu Bakar M.Z. (2009), Adsorption of phenol using activated carbon from waste tyre, Pertanika, The Journal of Science and Technology, 17, 371-380.
Bansal R.C. and Goyal M. (2005), Activated Carbon Adsorption, Taylor and Francis.

Belhachemi M. and Addoun F. (2011), Comparative adsorption isotherm and modelling of methylene blue onto activated carbons, Applied Water Science, 1, 111-117.

Bouchelta C., Medjram S.M. and Jean-Pierre Bellat O.B. (2008) Preparation and characterization of activated carbon from date stones by physical activation with steam, The Journal of Analytical and Applied Pyrolysis, 82, 70-77.

Boussahel R., Irinislimane H., Harik D. and Moussaoui K.M. (2009), Adsorption, kinetics and equilibrium studies on remoal of 4,-DDT from aqueous solutions using low cost adsorbents, Chemical Engineering Communications, 196,1547-1558.

Brito J.F., Ferreira L.O., Pereira M.C.R, Silva J.P. and Ramalho T.C. (2012), Adsorption of aromatic compounds under magnetic field influence, Water Air and Soil Pollution, 223, 545-3551.

Cecen F. and Aktas O. (2009), Activated Carbon for Water and Waste Water Treatment, Second Edition, Wiley-VCH, 2009.

Chakrabarty S. and Sarma H.P. (2011), A study on defluoridation capacity of betel nut coir charcoal from aqueous solution, Pollution Research, 30, 75-5.

Chatwal G.C. (2004), Synthetic Dyes, Third Edition, Himalaya Publishing House, Delhi.

Dehghani M.H., Sanaei D., Ali I. and Bhatnagar A. (2016), Removal of chromium(VI) from aqueous solution using treated waste newspaper as a low-cost adsorbent: Kinetic modeling and isotherm studies, Journal of Molecular Liquids, 215, 671-679.

Derylo-Marczewska A., Swiatkowski A., Biniak S. and Walczyk M. (2008), Effect of properties of chemically modified activated carbon and aromatic adsorbate molecule on adsorption from liquid phase, Colloids and Surfaces A: Physicochemical and Engineering Aspects, 327, 1-8.

Doke K.M., Yusufi M., Joseph R.D. and Khan E.M. (2016), Comparative adsorption of crystal and congo red on to $\mathrm{ZnCl} 2$ activated carbon, Journal of Dispersion Science and Technology, 37,1671-1681.

Dotto G., Campana-Filho S.P. and Almeida Pinto L.A. (2011), Frontiers in Biomaterials Chotosan Based Materials and its Applications, Volume-13, Benthem Science publishers, UAE.

Dowlatshahi S., Torbati A.R.H. and Loloei M. (2014), Adsorption of copper, lead and cadmium from aqueous solutions by activated carbon prepared from saffron leaves, Environmental Health Engineering and Management Journal, 1, 37-44.

Elhussien M.H., Hussein R.M., Nimir S.A. and Elsaim M.H. (2017), Preparation and characterization of activated carbon from palm tree leaves impregnated with zinc chloride for the removal lead (II) from aqueous solutions, American Journal of Physical Chemistry, 6, 59-69.

El-Sheikh A.H., Newman A.P., Al-Daffaee H.K., Phull S. and Cresswell N. (2004), Characterization of activated carbon prepared from a single cultivar of Jordanian Olive stones by chemical and physicochemical techniques, The Journal of Analytical and Applied Pyrolysis, 71, 151-164.

Goto T., Amano Y., Machida M. and Imazeki F. (2015), Effect of polarity of activated carbon surface, solvent and adsorbate on adsorption of aromatic compounds from liquid phase, Chemical and Pharmaceutical Bulletin, 63, 726-730. 
Haloi N., Sharma H.P. and Chakravarty P. (2013), Biosorption of lead (II) from water using heartwood charcoal of areca catechu: equilibrium and kinetics studies, Applied Water Science, 3, 559-565.

Hemashree K., Chaithra P. and Bhat J.I. (2016), Structural and adsorption properties of Areca husk carbon synthesized by physical, chemical and microwave activation methods, Journal of the Indian Chemical Society, 93, 1085-1094.

Iqbal M.J. and Ashiq M.N. (2007), Adsorption of dyes from aqueous solutions on activated charcoal, Journal of Hazardous Materials B, 139, 57-66.

Joshi S. and Adhikari M. (2016), Removal of Fluoride lons by Adsorption onto $\mathrm{Fe}_{2} \mathrm{O}_{3} /$ Areca Nut Activated Carbon Composite, Journal of the Institute of Engineering, 12, 175183.

Kemp W. (1991), Organic Spectroscopy, Third Edition, The Macmillan Press Ltd, Hong Kong.

Ketcha J.M., Dina D.J.D., Ngomo H.M. and Ndi N.J. (2012), Preparation and characterization of activated carbons obtained from maize cobs by zinc chloride activation, American Chemical Science Journal, 2, 136-160.

Lampman D.L., Pavia G.M., Kriz G.S. and Vyvyan J.R. (2013), Spectroscopy, Fourth Edition, Cenage Learning, New Delhi.

Lin G., Jiang J., Wu K. and Sun K. (2013), Effects of heat pretreatment during impregnation of the preparation of activated carbon from Chinese Fir wood by phosphoric acid activation, BioEnergy Research, 6, 1237-1242.

Martinez N.D., Rosa Beatriz Venturini R.B., Silve H.S., Gonzalez J.E. and Rodriguez A.M. (2009) Copper on activated carbon for catalytic wet air oxidation, Materials Research, 12, 45-50.

Mohanty K., Naidu J.T., Meikap B.C. and Biswas M.N. (2006), Removal of crystal violet from waste water by activated carbon prepared from rice husk, Industrial \& Engineering Chemistry Research, 45 5165-5171.

Muller-Hagedorn M., Bockhorn H., Krebs L. and Muller U. (2003), A comparative kinetic study on the pyrolysis of three different wood species, The Journal of Analytical and Applied Pyrolysis, 68/69, 231-249.

Muslim, Aprilia S., Suha T.A. and Fitri Z. (2017), Adsorption of $\mathrm{Pb}$ (II) ions from aqueous solution using activated carbon prepared from areca catechu shell: Kinetic, isotherm and thermodynamic studies, The Journal of the Korean Chemical Society, 61, 89-96.

Na C., Losso J.N., Marshall W.E. and Rao R.M. (2002), Freundlich isotherm of agricultural by-product-based powdered activated carbon in a geosmin-water system, Bioresource Technology, 85, 131-135.

Nabili A., Fattoum A., Passas R. and Elaloui E. (2016), Extraction and characterization of cellulose from date palm seeds (Phoenix dactylifera L.), Cellulose Chemistry and Technology, 50, 1015-1023.

Nath K., Thummar M., Vaghela M. and Jani P. (2008), Sorption of phenol from aqueous solution using activated carbon prepared from Manilkara Zapota seed, Indian Journal of Chemical Technology, 15, 533-540.

Omidi-Khaniabadi Y., Jafari A., Nourmoradi H., Taheri F. and Saeedi S. (2015), Adsorption of 4-Chlorophenol from aqueous solution using activated carbon synthesized from aloe vera green wastes, Journal of Advances in Environmental Health Research, 3, 1-10.
Pahari S. (2011), Physical Chemistry Volume II, Second Edition New Central Book Agency(P) Ltd, Kolkata, 2011.

Park S., Baker J.O., Himmel M.E., Parilla P.A. and Johnson D.K. (2010) Cellulose crystallinity index: measurement techniques and their impact on interpreting cellulase performance, Biotechnologhy for Biofuels, 3, 10.

Radovic L.R., Biniak S., Swaiatkowski A. and Pakula M., (2001), Chemistry and Physics of Carbon, Marcel Dekker Inc., New York.

Rauf S., Nagapadma M. and Rao R.R. (2015), Removal of Harmful Textile Dye Congo red from aqueous solution using chitosan and chitosan beads modified with CTAB, International Journal of Engineering Research and Applications, 5, 75-82.

Sa Y., Guo Y., Feng X., Wang M., Li P., Gao Y., Yang X. and Jiang T. (2017), Are different crystallinity index - caluculating methods of hydroxyapatite efficient and consistent, New Journal of Chemistry, 41, 5723-5731.

Sawyer C.N., McCarty P.L. and Parkin G.F.(1994), Chemistry for Environmental Engineering, Fourth Edition, McGraw-Hill International Editions, Singapore.

Yang K., Peng J., Srinivasakannan C., Zhang L., Xia H. and Duan X. (2010), Preparation of high surface area activated carbon from coconut shells using microwave heating, Bioresource Technology, 101, 6163-6169. 